\title{
RANCANG BANGUN ALAT PRAKTIKUM GERBANG LOGIKA DASAR BERBASIS OP-AMP
}

\author{
Abdul Karim Syahbani' ${ }^{1}$, Ana Setiana1, Fikynindita Ika Kharisma1 \\ 1 Program Studi Pendidikan Fisika UIN Sunan Gunung Djati \\ E-mail: 1162070001@student.uinsgd.ac.id
}

\begin{abstract}
ABSTRAK
Penggunaan teknologi sekarang ini semakin berkembang khususnya dalam elektronika. Dalam ilmu elektronika terdapat suatu komponen yang merupakan gabungan dari komponen elektronika lainnya, komponen tersebut adalah IC (Integrated Circuit). Di dalam IC terdapat suatu rangkaian logika yang disebut gerbang logika. Gerbang (gate) berfungsi untuk menggambarkan hubungan antara masukan dan keluaran. Perancangan alat ini bertujuan untuk mempermudah peserta didik untuk memahami konsep gerbang logika menggunakan alat elektronika yang bernama OP-AMP. Metode yang digunakan adalah dengan melakukan praktikum. Model praktikum yang digunakan adalah inkuiri dimana siswa dituntut untuk mengembangkan ide yang didapatkan dari pembelajaran di kelas. Hasilnya percobaan dapat disimpulkan bahwa gerbang logika dapat membuktikan fungsi dari tabel kebenaran gerbang logika masing-masing gerbang logika mempunyai cara kerja dan karakteristik yang berbedabeda yaitu; Gerbang logika NOT merupakan pembalik yang berarti output yang dihasilkan merupakan kebalikan dari inputnya, Gerbang logika AND adalah gerbang logika yang memiliki 2 input atau lebih, Gerbang logika OR memiliki 2 atau lebih sinyal input, dan Gerbang logika NOR adalah inverter dari OR. Untuk menentukan gerbang logika sesuai dengan tabel kebenaran ditunjukan dengan nyala lampu pada alat tersebut jika 0 diwakili dengan keluaran lampu mati, sedangkan jika 1 diwakili dengan keluaran lampu hidup.
\end{abstract}

Kata kunci: Aljabar Boolean, rangkaian gerbang logika kombinasi, LED.

\begin{abstract}
The use of technology is now growing especially in electronics. In electronics there is a component that is a combination of other electronic components, the component is IC (Integrated Circuit). In IC there is a series of logic called Logic gates. The gate serves to illustrate the relationship between input and output. The design of this tool aims to make it easier for learners to understand the concept of logic gates using an electronic tool called OP-AMP. The method used is to do the practicum. The Model of practicum used is inquiry where students are required to develop ideas gained from classroom learning. The results of the experiment can be concluded that the logic gate can prove the function of the table truth of the logic gate of each logic gate has different workways and characteristics that are; The NOT logic gate is a counterattack which means the resulting output is the opposite of its input, the logic gate AND is a logic gate that has 2 inputs or more, the gate logic OR has 2 or more input signals, and the NOR gate logic is an inverter from OR. To determine the gate of the logic according to the truth table is indicated by the light on the device if 0 is represented by the output of the lamp die, while if 1 is represented by the output of the lamp.
\end{abstract}

Keywords: Boolean Algebra, combinational range of logic, LED.

DOI: https://doi.org/10.15575/jotalp.v3i2.6552

Received: 1 Juli 2018 ; Accepted: 30 Juli 2018 ; Published: 1 September 2018 


\section{PENDAHULUAN}

Di era globalisasi ini kemajuan teknologi elektronika saat ini berkembang pesat. Komponen-komponen dari semi konduktor sekarang telah di kemas dalam satu paket yang berfungsi sesuai dengan yang diinginkan kemasan ini disebut dengan rakaian terpadu (integral circuit) salah satu dari rangkaian tersebut adalah Op-Amp (operational Amplifier), yang befungsi sebagai penguat aktif dengan menggunakan perangkat ini maka dapat di buat berbagai macam rangkaian salah satunya system digital pada benda elektronik dan apa hubungannya dengan gerbang logika. Gerbang logika merupakan dasar dari pembentukan system digital yang kita kenal saat ini. Missal saja pada computer yang sehari-hari kita pakai merupakan aplikasi langsung dari penggunaan gerbang logika (Fauzi, 2005).

Gerbang (gate) dalam rangkaian logika merupakan fungsi yang menggambarkan hubungan antara masukan dan keluaran. Untuk menyatakan gerbang-gerbang tersebut biasanya digunakan simbol-simbol tertentu. Ada beberapa standar penggambaran simbol. Salah satu standar simbol yang populer adalah MIL-STD-806B yang dikeluarkan oleh Departemen Pertahanan Amerika Serikat untuk keperluan umum pada bulan Februari 1962. Untuk menunjukkan prinsip kerja tiap gerbang (atau rangkaian logika yang lebih kompleks) dapat digunakan beberapa cara. Cara yang umum dipakai antara lain adalah tabel kebenaran (truth table) dan diagram waktu (timing diagram). Karena merupakan rangkaian digital, tentu saja level kondisi 2 yang ada dalam tabel atau diagram waktu hanya dua macam, yaitu logika 0 (low, atau hight) dan logika 1 (atau False, atau true). Kondisi lain yang mungkin ada adalah kondisi X (level bebas, bisa logika 1 atau 0), dan kondisi high impedance (impedansi tinggi). Kondisi X biasanya ada di masukan gerbang dan menyatakan bahwa apa pun logika masukannya (logika 0 atau 1) tidak akan mempengaruhi logika keluaran yang dihasilkan (Setiawan, 2014).

Prosesor sebagai otak penggerak segala kegiatan baik itu mengetik, mendengarkan music, main game dan sebagainya merupakan gabungan dari beberapa gerbang logika yang tersusun dalam suatu susunan yang sering kita dengar dengan istilah chip dan kumpulan dari chip terbentuklah IC (integrated circuit) (Darmawan, 2009). Gerbang logika yang umum dipakai merupakan gabungan/modifikasi dari gerbang dasar yaitu gerbang AND, NOT, dan OR dengan memodifikasi gerbang dasar tersebut akan didapat gerbang baru seperti gerbang NAND, NOR dan XOR. Gerbang dasar ini terdiri dari satu atau lebih input dan hanya satu output. Untuk input dan output menggunakan dua taraf tegangan, yaitu taraf rendah (LOW 0,2-2 VOLT) dan taraf tinggi (HIGHT 3,8-5 VOLT). Taraf rendah dinyatakan dengan 0 atau L sedangkan taraf tinggi dinyatakan dengan 1 atau $\mathrm{H}$.

Gerbang logika atau sering juga disebut gerbang logika boolean merupakan sebuah sistem pemrosesan dasar yang dapat memproses inputinput yang berupa bilangan biner menjad isebuah output yang berkondisiyang akhirnya digunakan untuk proses selanjutnya.Gerbang logika dapat mengkondisikan input-input yang masuk kemudian menjadikannya sebuah output yang sesuai dengan apa yang ditentukan olehnya.

Sebenarnya gerbang logika inilah yang melakukan pemrosesan terhadap segala sesuatu yang masuk dan keluar ke dan dari computer Maka dari itu, sebenarnya sebuah perangkat komputer merupakan sebentuk kumpulan gerbang-gerbang digital yang bekerja memproses sesuatu input, menjadi output yang diinginkan. Gerbang Logika adalah rangkaian dengan satu atau lebih dari satu sinyal masukan tetapi hanya menghasilkan satu sinyal berupa tegangan tinggi atau tegangan rendah. Dikarenakan analisis gerbang logika dilakukan dengan Aljabar Boolean maka gerbang logika sering juga disebut Rangkaian logika.

Adapun rumusan masalah dari penulisan karya ilmuah ini adalah bagaimana cara menerapkan dari teori Aljabar Bolean pada sebuah penguat dengan mencocokan pada tabel kebenaran yang telah ada dalam teknologi elektronik di kehidupan sehari-hari.

Gerbang-gerbang dasar logika merupakan elemen rangkaian digital dan rangkaian digital 
merupakan kesatuan dari gerbang-gerbang logika dasar yang membentuk fungsi pemrosesan sinyal digital (Narendro Arifia, 2013). Gerbang dasar logika terdiri dari 3 gerbang utama, yaitu AND Gate, OR Gate, dan NOT Gate. Gerbang lainnya seperti NAND Gate, NOR Gate, EX-OR Gate dan EX-NOR Gate merupakan kombinasi dari 3 gerbang logika utama tersebut. Berikut adalah macam-macam gerbang logika menurut (Kurniawan, 2013).

A. Gerbang Logika AND

Gerbang AND merupakan salah satu gerbang logika dasar yang memiliki 2 buah saluran masukan (input) atau lebih dan sebuah saluran keluaran (output). Suatu gerbang AND akan menghasilkan sebuah keluaran binertergantung dari kondisi masukan dan fungsinya. Prinsip kerja dari gerbang AND adalah kondisi keluaran (output) akan berlogic 1 bila semua saluran masukan (input) berlogic 1. Selain itu output akan berlogic 0 . Simbol gerbang logika AND 2 input:Gerbang Logika OR

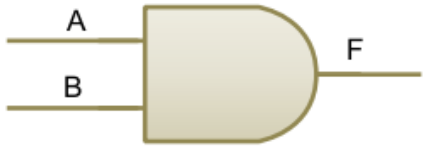

Gambar 1. Simbol Gerbang AND

dengan persamaan output logika fungsi AND adalah $\mathrm{F}=\mathrm{A} \cdot \mathrm{B}$ (dibaca $\mathrm{F}=\mathrm{A}$ AND $\mathrm{B}$ ). Tabel kebenaran:

Tabel 1. Tabel Kebenaran Gerbang AND

\begin{tabular}{|c|c|c|}
\hline \multicolumn{2}{|c|}{ Input } & Output \\
\hline A & B & $\mathrm{F}$ \\
\hline 0 & 0 & 0 \\
\hline 0 & 1 & 0 \\
\hline 1 & 0 & 0 \\
\hline 1 & 1 & 1 \\
\hline
\end{tabular}

B. Gerbang Logika NOT

Gerbang OR merupakan salah satu gerbang logika dasar yang memiliki 2 buah saluran masukan (input) atau lebih dan sebuah saluran keluaran (output). Berapapun jumlah saluran masukan yang dimiliki oleh sebuah gerbang $\mathrm{OR}$, maka tetap memiliki prinsip kerja yang sama dimana kondisi keluarannya akan berlogic 1 bila salah satu atau semua saluran masukannya berlogic 1 . Selain itu output berlogic 0 .

Simbol gerbang logika OR 2 input adalah:

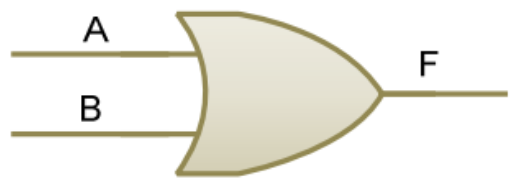

Gambar 2. Simbol Gerbang OR dengan persamaan output logika fungsi OR adalah $\mathrm{F}=\mathrm{A}+\mathrm{B}$ (dibaca $\mathrm{F}=\mathrm{A}$ OR B). Tabel kebenaran:

Tabel 2. Tabel Kebenaran Gerbang OR

\begin{tabular}{ccc}
\hline Input & & Output \\
$\mathrm{A}$ & $\mathrm{B}$ & $\mathrm{F}$ \\
\hline 0 & 0 & 0 \\
0 & 1 & 1 \\
1 & 0 & 1 \\
1 & 1 & 1 \\
\hline
\end{tabular}

C. Gerbang Logika NOT

Gerbang NOT sering disebut dengan gerbang inverter. Gerbang ini merupakan gerbang logika yang paling mudah diingat. Gerbang NOT memiliki 1 buah saluran masukan (input) dan 1 buah saluran keluaran (output). Gerbang NOT akan selalu menghasilkan nilai logika yang berlawanan dengan kondisi logika pada saluran masukannya. Bila pada saluran masukannya berlogic 1 maka pada saluran keluarannya akan berlogic 0 dan sebaliknya.

Simbol gerbang logika NOT:

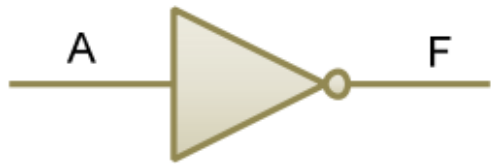

Gambar 3. Simbol Gerbang NOT dengan persamaan output logika fungsi NOT adalah $F=\bar{A}$.

Tabel 3. Tabel Kebenaran Gerbang NOT

\begin{tabular}{cc}
\hline Input & Output \\
A & $\mathrm{F}$ \\
\hline 0 & 1 \\
1 & 0
\end{tabular}

D. Gerbang Logika NAND 
Gerbang NAND merupakan kombinasi dari gerbang AND dengan gerbang NOT dimana keluaran gerbang AND dihubungkan ke saluran masukan dari gerbang NOT. Karena keluaran dari gerbang AND di "NOT" kan maka prinsip kerja dari gerbang NAND merupakan kebalikan dari gerbang AND. Outputnya merupakan komplemen atau kebalikan dari gerbang AND, yakni memberikan keadaan level logic 0 pada outputnya jika dan hanya jika keadaan semua inputnya berlogika 1. Simbol gerbang NAND:

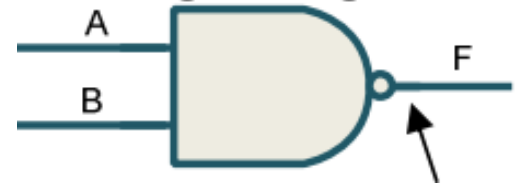

Gambar 4. Simbol Gerbang NAND

Gerbang NAND merupaka kombinasi AND dan NOT sehingga juga dapat ditulis sebagai:

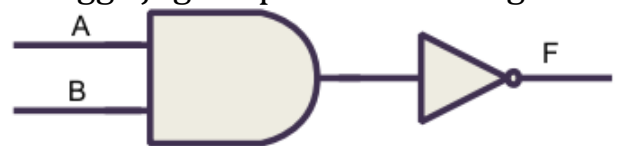

Gambar 5. Simbol Gerbang NAND Kombinasi Persamaan output logika fungsi NAND adalah $F=\overline{A . B}$. Tabel kebenaran gerbang NAND adalah sebagai berikut:

Tabel 4. Tabel Kebenaran Gerbang NAND

\begin{tabular}{|c|c|c|}
\hline \multicolumn{2}{|c|}{ Input } & Output \\
\hline A & B & $\mathrm{F}$ \\
\hline 0 & 0 & 1 \\
\hline 0 & 1 & 1 \\
\hline 1 & 0 & 1 \\
\hline 1 & 1 & 0 \\
\hline
\end{tabular}

E. Gerbang Logika NOR

Sama halnya dengan NAND Gate, gerbang NOR merupakankombinasi dari gerbang OR dengan gerbang NOT dimana keluaran gerbang OR dihubungkan ke saluran masukan dari gerbang NOT. Karena keluaran dari gerbang OR di "NOT" kan maka prinsip kerja dari gerbang NOR merupakan kebalikan dari gerbang OR. Outputnya merupakan komplemen atau kebalikan dari gerbang OR, yakni memberikan keadaan level logic 0 pada outputnya jika salah satu atau lebih. Inputnya berlogika 1. Simbol Gerbang Logika NOR:

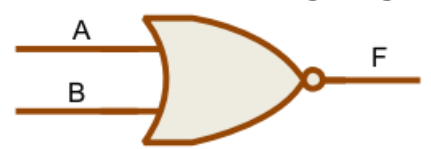

Gambar 6. Simbol Gerbang Logika NOR Gerbang logiika NOR merupakan hasil kombinasi dari gerbang OR dan NOT sehingga juga dapat digambarkan sebagai berikut:

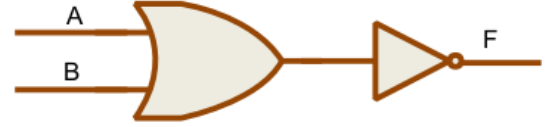

Gambar 7. Simbol Gerbang NOR Kombinasi Persamaan output logika fungsi NOR adalah $F=\overline{A+B}$. Tabel kebenara untuk gerbang NOR adalah sebagai berikut:

Tabel 5. Tabel Kebenaran Gerbang NOR

\begin{tabular}{|c|c|c|}
\hline \multicolumn{2}{|c|}{ Input } & Output \\
\hline A & B & $\mathrm{F}$ \\
\hline 0 & 0 & 1 \\
\hline 0 & 1 & 1 \\
\hline 1 & 0 & 1 \\
\hline 1 & 1 & 0 \\
\hline
\end{tabular}

\section{METODE PENELITIAN}

Penelitian ini dilakukan dengan menggunakan metode eksperimen. Peralatan yang digunakan untuk mebuat alat praktikum ini adalah IC 74LS04 (ICNOT), IC 74LS08 (IC AND), IC 74LS32 (IC OR), IC 74LS02 (IC NOR), Dudukan IC 14p, Banana Plus, Banana post, Saklar Togel, LED, PCB, Spicer PCB, Papan krani, kabel, kabel 071, timah, resistor, dan power suplay elektrik (SMPS). Desain rangka alat yang dibuat adala sebagai berikut: 


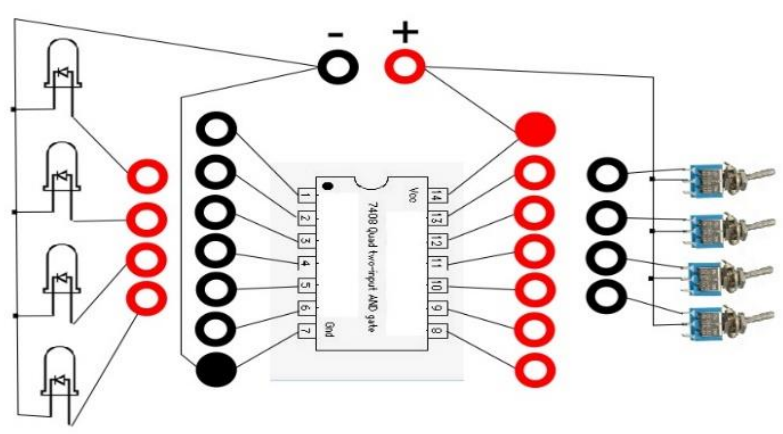

Gambar 8. Desain Alat Rangkaian Gerbang Logika

\section{HASIL DAN PEMBAHASAN}

Masalah yang terjadi di sekolah-sekolah terutama di sekolah menengah kejuruan yang membahas terkait materi elektronika adalah siswa seringkali mengalami kesulitan dalam mempelajari gerbang logika. Gerbang logika menyangkut angka-angka yang ada pada suatu alat elektronika yang hanya berjumlah dua angka yaitu 1 dan 0. Materi gerbang logika ini sering dianggap materi yang abstrak sehingga siswa akan kesulitan memahami dan mengaplikasikannya dalam kehidupan sehari-hari.

Berdasarkan adanya alat praktikum gerbang logika dasar tersebut, maka data yang didapat adalah sebagai berikut:

Tabel 6. Hasil Percobaan Gerbang AND Input Output Nyala LED

\begin{tabular}{cccc}
$\mathrm{A}$ & $\mathrm{B}$ & $\mathrm{Y}$ & $(\mathrm{L} / \mathrm{H})$ \\
\hline 0 & 0 & 0 & $\mathrm{~L}$ \\
0 & 1 & 0 & $\mathrm{~L}$ \\
1 & 0 & 0 & $\mathrm{~L}$ \\
1 & 1 & 1 & $\mathrm{H}$ \\
\hline
\end{tabular}

Prinsip kerja dari gerbang AND ini adalah keadaan LED menyala jika masukan (input) menghasilkan keluaran (output) berlogic 1 yaitu ketika kedua masukan atau saklar pada posisi ON atau HIGHT. Jika salah satunya saklar pada posisi OFF atau LOW maka LED tidak menyala.

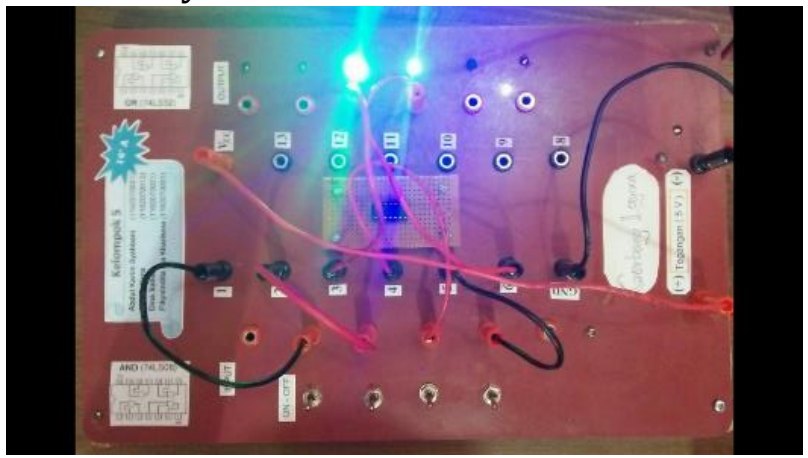

Gambar 9. Gambar Pengujian Gerbang AND

Tabel 7. Hasil Percobaan Gerbang OR

\begin{tabular}{cccc}
\multicolumn{2}{c}{ Input } & Output & $\begin{array}{c}\text { Nyala LED } \\
\text { (L/H) }\end{array}$ \\
$\mathrm{A}$ & $\mathrm{B}$ & $\mathrm{Y}$ & $\mathrm{L}$ \\
0 & 0 & 0 & $\mathrm{~L}$ \\
0 & 1 & 0 & $\mathrm{~L}$ \\
1 & 0 & 0 & $\mathrm{H}$ \\
1 & 1 & 1 & \\
\hline
\end{tabular}

Prinsip kerja dari gerbang OR ini adalah keadaan LED menyala jika masukan (input) menghasilkan keluaran (output) berlogic 1 yaitu ketika kedua masukan atau saklar pada posisi ON atau HIGHT. Jika salah satunya saklar pada posisi OFF atau Low LED akan tetap menyala, LED tidak menyala dalam keadaan kedua masukan berlogic 0. Gerbang NOR ini merupakan inverter dari gerbang OR.

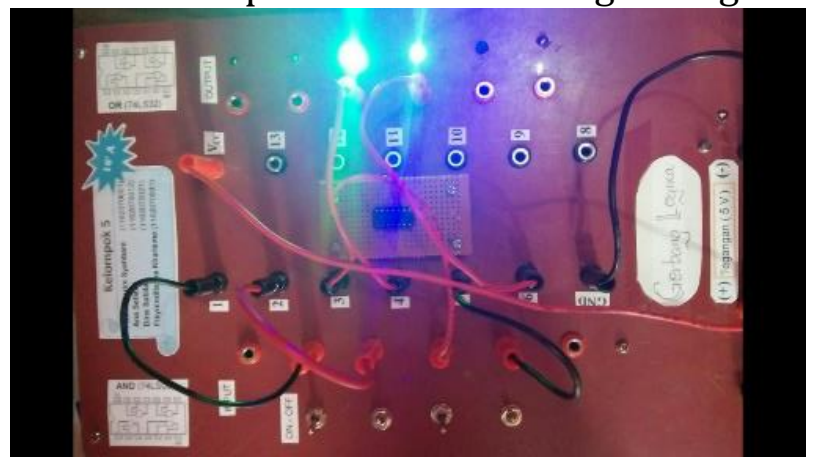

Gambar 10. Pengujian Gerbang OR 


\section{Tabel 8. Hasil Pengujian Gerbang NOT \\ Input Output Nyala LED}

\begin{tabular}{ccc}
$\mathrm{A}$ & $\mathrm{Y}$ & $(\mathrm{L} / \mathrm{H})$ \\
\hline 1 & 0 & $\mathrm{~L}$ \\
0 & 1 & $\mathrm{H}$ \\
\hline
\end{tabular}

Prinsip kerja dari gerbang NOT ini adalah keadaan LED menyala jika masukan (input) menghasilkan keluaran (output) berlogic 1 yaitu ketika kedua masukan atau saklar pada posisi OFF atau LOW, hal ini dikarenakan gerbang NOT itu artinya adalah kebalikan (inverter). Jika output berlogic 0 maka hasil pada gerbang logika NOT ini adalah kebalikan yaitu berlogic 1, sehingga LED dapat menyala.

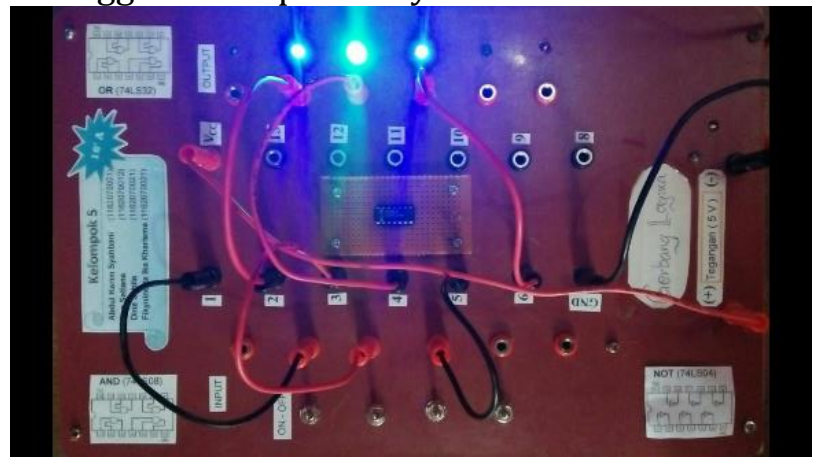

Gambar 11. Pengujian Gerbang NOT Tabel 9. HasilPengujian Gerbang NOR

\begin{tabular}{cccc}
\multicolumn{2}{c}{ Input } & Output & Nyala LED \\
$\mathrm{A}$ & $\mathrm{B}$ & $\mathrm{Y}$ & $(\mathrm{L} / \mathrm{H})$ \\
\hline 0 & 0 & 1 & $\mathrm{H}$ \\
0 & 1 & 0 & $\mathrm{~L}$ \\
1 & 0 & 0 & $\mathrm{~L}$ \\
1 & 1 & 0 & $\mathrm{~L}$ \\
\hline
\end{tabular}

Prinsip kerja dari gerbang NOR ini adalah keadaan LED menyala jika masukan (input) menghasilkan keluaran (output) berlogic 1 yaitu ketika kedua masukan atau saklar pada posisi ON atau HIGHT. Jika salah satunya saklar pada posisi OFF atau Low LED akan tetap menyala, LED tidak menyala dalam keadaan kedua masukan berlogic 0 . Gerbang NOR ini merupakan inverter dari gerbang $\mathrm{OR}$.

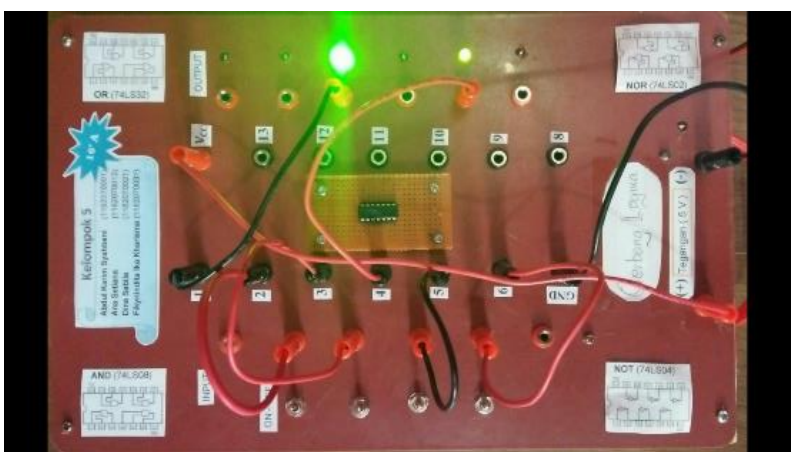

Gambar 12. Pengujian Gerbang NOR

Alat ini mempermudah pengetahuan siswa dalam memahami tabel kebenaran gerbang logika dengan cara praktikum langsung atau membuktikannya secara langsung. Dapat diketahui bahwa gerbang logika pada AND, NOT, OR, dan NOR memiliki cara kerja dan karakteristik tersendiri. Seperti halnya pada gerbang logika AND yaitu untuk mendapatkan output bernilai 1, maka sinyal input yang diberikan harus 1 dan 1 atau keseluruhan inputnya harus berlogika 1. Artinya agar LED dapat menyala, maka input yang digunakan harus bernilai 1 .

Alat praktikum ini menggunakan jenis IC yang berbeda-beda tergantung gerbang logika apa yang akan dibuktikan. Sehingga dapat disimpulkan bahwa alat praktikum gerbang logika untuk SMK ini dapat mempermudah siswa dalam memahami tabel kebenaran gerbang logika secara langsung.

Sedangkan kelemahan ataupun kekurangan dari IC Gerbang logika ini adalah mudah terjadinya kebakaran atau konslet pada IC terhadap alat, sehingga menyebabkan IC rusak. Hal ini disebabkan karena sifat atau karekteristik yang dimiliki IC yaitu mudah rusak dan mudah panas jika di aliri sumber tegangan diatas $5 \mathrm{~V}$. oleh karena itu pada alat yang kami buat kami memasangkan suatu alat untuk mengubah sumber tegangan AC $20 \mathrm{~V}$ menjadi tegangan AC 5V untuk mencegah kerusakan pada IC. Selain IC mudah panas kaki IC juga mudah patah atau bengkok yang dapat menyebabkan IC rusak oleh karena itu untuk penggunaan IC harus berhatihati dan jangan sampai memasang IC dengan posisi yang salah/terbalik, dengan catatan ujung 
IC nomor satu adalah bagian yang ada tanda titiknya.

Berdasarkan permasalahan yang telah diungkapkan, maka kami membuat penelitian suatu alat yang berkaitan dengan gerbang logika dasar. Tujuan dari pembuatan alat tersebut adalah untuk memudahkan siswa dalam memahami dan mempelajari angka 0 dan 1 yang ada pada gerbang logika serta membuat materi abstrak menjadi lebih konkret.

\section{KESIMPULAN}

Dari laporan alat praktikum yang kami buat mengenai penerapan pada materi Gerbang Logika Dasar, kami ingin membuktikan fungsi dari gerbang logika dan prinsip kerjanya melalui media alat yang kami buat. Hasilnya, kami dapat membuktikan fungsi dari tabel kebenaran gerbang logika dengan alat gerbang logika ini. Berdasarkan hal tersebut, dapat dibuat suatu kesimpulan bahwa masing-masing gerbang logika mempunyai cara kerja dan karakteristik yang berbeda-beda yaitu:

a. Gerbang logika NOT merupakan pembalik yang berarti output yang dihasilkan merupakan kebalikan dari inputnya. Untuk menghasilkan output berlogika 1, maka input yang diberikan harus 0.

b. Gerbang logika AND adalah gerbang logika yang memiliki 2 input atau lebih. Untuk mendapatkan output bernilai 1, maka sinyal input yang diberikan harus 1 dan 1 atau keseluruhan inputnya harus berlogika 1 .

c. Gerbang logika OR memiliki 2 atau lebih sinyal input. Jika ingin input berlogika 1 , maka salah satu atau keseluruhan inputnya harus berlogika 1 .

d. Gerbang logika NOR adalah inverter dari OR.

\section{DAFTAR PUSTAKA}

Darmawan, A. (2009). Perancangan Rangkaian Terpadu Penguat Operasional Untuk Pengatur Nada. Jurnal EECCIS, 3(2), 17 - 23.

Fauzi. (2005). Operasi Matematika dengan Menggunakan Rangkaian OP-AMP. JURNAL MEDIA TEKNIK, 2(3), 5-10.
Kurniawan, i. (2013). Gerbang Logika dan Sistem Bilangan Gerbang Logika. Diktat Elektronika Digital.

Narendro Arifia, S. (2013). Sistem Digital. Jakarta: PT.Pustaka Mandiri

Setiawan, R. (2014). [Laporan Praktikum Eldas] Gerbang Logika And, Or, dan Not. Jurnal Elektronika. 